\title{
Climate Change and Groundwater: Vulnerability, Adaptation and Mitigation Opportunities in India
}

\author{
Khajuria Anupam and Kanae Shinjiro
}

\begin{abstract}
Climate change is one of the most important global environmental challenges, with implications for food production, water supply, health, energy, etc. Addressing climate change requires a good scientific understanding as well as coordinated action at national and global level. During the last 40 years, India has witnessed a decline in gravity-flow irrigation and the rise of a booming 'water-scavenging' irrigation economy through millions of small and private tube wells. The groundwater has become at once critical and threatened. Climate change will act as a force multiplier; it will enhance groundwater's criticality for drought-proofing agriculture and simultaneously multiply the threat to the resource. India's groundwater hotspots are western and peninsular regions. These regions are critical for climate change mitigation as well as adaptation. To achieve both, India needs to make a transition from surface storage to 'managed aquifer storage' as the centre pin of its water strategy with proactive demand- and supply-side management components.
\end{abstract}

Index Terms-Groundwater, climate change, adaptation, environmental, mitigation

\section{INTRODUCTION}

For many decades, water utilities have proactively assessed the ability of their systems to provide a reliable supply of drinking water or adequate wastewater services under assumptions of population change, municipal expansion, technological innovation and changes in regulations. These were the foreseeable challenges utilities addressed to ensure that rate payers received high quality water services at minimal cost [1]. Historically, utilities assumed stationary of climate in their water resource planning - the idea that natural systems fluctuate within an unchanging envelope of variability. Recently, however, this assumption has been challenged, forcing managers to rethink future water resources planning and management with regard to climate change [2]. Climate change, according to the definition by the Intergovernmental Panel on Climate Change [3], refers to any change in climate over time whether due to natural variability or as a result of human activity. The United Nations Framework Convention on Climate Change defines

Manuscript received December 10, 2012; revised March 1, 2013. This work was financially supported by program "Long-term Vision for the Sustainable Use of the World's Freshwater Resources" through Core Research for Evolutional Science and Technology (CREST) under the Japan Science and Technology Agency .

The authors are with Department of Mechanical \& Environmental Informatics, Tokyo Institute of Technology, 2-12-1 Ookayama, Meguro-ku, Tokyo 152-8552, Japan (e-mail: khajuria.a.aa@m.titech.ac.jp). climate change as, "a change of climate which is attributed directly or indirectly to human activity that alters the composition of the global atmosphere and which is in addition to natural climate variability observed over comparable time periods" [4].

Vulnerability of water resources will affects the energy sector, depends on its rivers to provide power generation to its hydro-electric plants and cooling water to its nuclear and thermal generation plants. As the flow rates of rivers decline with climate change, the country's ability to meet its full domestic electricity demand will be at greater risk [5]. If water reserves and releases are well managed, small changes in precipitation and evaporation need have little impact on hydro-electric generation. Reduced river flow coupled with an increased demand for irrigation water is very likely to reduce electricity generation from these plants.

\section{IMPACT OF CLIMATE CHANGE AND HydRology}

Much of the solar energy received by the earth is used to drive the hydrological cycle, higher levels of solar energy trapped in the atmosphere will lead to intensification in cycle, result the changes in precipitation patters. These changes will result in increased floods and drought, which will have significant impacts on the availability of freshwater. These impacts on freshwater will be further compounded by rising sea level and melting glaciers [6]. Rising global temperatures will lead to an intensification of the hydrological cycle, resulting in dryer dry seasons and wetter rainy seasons and subsequently heightened risks of more extreme and frequent floods and drought (Table I). Changing climate will also have significant impacts on the availability of water, as well as the quality and quantity of water that is available and accessible. Melting glaciers will increase flood risk during the rainy season and strongly reduce dry-season water supplies to one-sixth of the world's population [7].

The latest science suggests that the Earth's average temperature will rise by even more than 5 or $6^{\circ} \mathrm{C}$ if emissions continue to grow and positive feedbacks amplify the warming effect of greenhouse gases (e.g. release of carbon dioxide from soils or methane from permafrost). This level of global temperature rise would be equivalent to the amount of warming that occurred between the last age and today - and is likely to lead to major disruption and large-scale movement of population. Such "socially contingent" effects could be catastrophic, but are currently very hard to capture with current models as temperatures would be so far outside human experience [6] 
TABLE I: HIGHLIGHTS OF POSSIBLE CLIMATE IMPACTS ON WATER

\begin{tabular}{|c|c|}
\hline $\begin{array}{l}\text { Temperature } \\
\text { rise }\left({ }^{0} \mathrm{C}\right)\end{array}$ & Water level \\
\hline $1^{0} \mathrm{C}$ & $\begin{array}{l}\text { Small glaciers in the Andes disappear completely, } \\
\text { threatening water supplies for } 50 \text { million people. }\end{array}$ \\
\hline $2^{0} \mathrm{C}$ & $\begin{array}{l}\text { Potentially } 20-30 \text { percent decrease in water availability } \\
\text { in some vulnerable regions, e.g. Southern Africa and } \\
\text { Mediterranean. }\end{array}$ \\
\hline $3^{0} \mathrm{C}$ & $\begin{array}{l}\text { In Southern Europe, serious droughts occur once every } 10 \\
\text { years } 1-4 \text { billion more people suffer water shortages, } \\
\text { while } 1-5 \text { billion gain water, which may increase flood } \\
\text { risk. }\end{array}$ \\
\hline $4^{0} \mathrm{C}$ & $\begin{array}{l}\text { Potentially } 30-50 \text { percent decrease in water availability in } \\
\text { Southern Africa and Mediterranean. }\end{array}$ \\
\hline $5^{0} \mathrm{C}$ & $\begin{array}{l}\text { Possible disappearance of large glaciers in Himalayas, } \\
\text { affecting one quarter of China's population and hundreds } \\
\text { of millions in India. }\end{array}$ \\
\hline
\end{tabular}

\section{A. Floods and Droughts}

The IPCC contends that current water management practices may not be robust enough to cope with the impacts of climate change on water supply reliability, flood risk, health, agriculture, energy and aquatic ecosystems. In many locations, water management cannot even satisfactorily cope with current climate variability, resulting in large flood and drought damages. Climatic and non-climatic factor, such as population growth and damage potential will exacerbate these problems in the future. As a first step, improved incorporation of information about current climate variability into water-related management would assist countries towards adaptation to long-term climate change impacts [6]. The combined and interacting forces of climate change and socio-economic drivers results in a continuously increasing demand for finite water resources for which there are no substitutes. When water resources of acceptable quality can no longer be provided in sustainable quantities, the outcome can lead to overexploitation of aquatic ecosystems. The ultimate losers are the exploited aquatic ecosystem and the organisms (including humans) dependent on them for survival and well-being.

Warmer average global temperature mean greater evaporation, with a warmer atmosphere able to hold more moisture aloft that can fall as precipitation, increasing the potential for flooding. There are a number of factors that contribute to flood risks implied by a warmer climate, including:

- more frequent wet spells in middle/ high latitude winters;

- more intense mid-latitude storms;

- increased frequency of extreme precipitation events;

- increased magnitudes of precipitation events of high intensity; and

- land use changes and surface degradation (for example, deforestation and urbanization).

\section{B. Rising Sea Levels}

Melting of ice and thermal expansion of oceans as a result of increased average temperature will result in rising sea level. Sea levels have already risen between $10-20 \mathrm{~cm}$ over pre-industrial average and are expected to rise further by up to one metre during the 21 st Century [7]. Changes in sea level will increase coastal erosion, flooding of wetlands and lowlands. It will also have a significant impact on the availability of freshwater:
- groundwater resources in coastal plains are potentially vulnerable to salinisation from rising sea levels, due to their low elevation and hydraulic gradient;

- salt water intrusion in the lower reaches of the deltas will be exacerbated by predicted rises in sea levels; and

- reduced protective capacity from extreme storms and floods, as higher sea levels provide a higher base for storm surges.

\section{Melting Glaciers}

Scientists are especially concerned about the Arctic, where the effects of climate change are being felt more quickly and severely than anywhere else on the planet. Arctic temperatures increased by about 5 degree during the 20th Century - 10 times faster than the global average. Snow cover has declined by 10 percent in the mid-high latitudes of the Northern Hemisphere since the late 1960s and, in the Russian Arctic, buildings are collapsing because of thawing permafrost under the foundations [8].

The dramatic changes occurring in the Arctic are being felt around the world: melting glaciers contribute to rising sea level, and also increased flash floods as river basins fill more quickly and with a greater volume of water, with the resulting impacts on freshwater availability. During dry season, water supplies are dramatically reduced due to reduced availability of glacial melt to fill streams and rivers. Furthermore, thawing permafrost in the Arctic is releasing methane, a gas which has a very high global warming impact. This will act as a further feedback mechanism which accelerates ongoing climate change.

\section{Changes IN THE QUANTITY, QUALITY AND ACCESSIBILITY OF WATER SUPPLY}

\section{A. Quantity}

Many of the world's countries already struggle under existing water stress from pressure such as irrigation demands, industrial pollution and water borne sewerage. These pressure will be significantly exacerbated by climate change, for many regions will result in reduced rainfall and increasing temperature, further reducing the availability of water for drinking, household use, agriculture and industry. As these competing demands intensify under climate change, effective governance for balancing water demand will become essential, particularly in the face of strong pressure to priorities industrial uses over other uses such as drinking, agricultural supplies. The Stockholm Environment Institute estimates that, based on only a moderate climate change, by 2025 the proportion of the world's population living in countries of significant water stress will increase from approximately 34 percent to 63 percent [9]. The consequences for water supply include smaller flows in springs and rivers, and decreasing groundwater level.

The annual per capita water availability in 1970 was 4,782 $\mathrm{m}^{3}$, when the total population was only 482 million. The population increased to 1,014 million in 2000, whereas the annual per capita water availability reduced drastically to $1,949 \mathrm{~m}^{3}$. According to our simulation about the future prediction, the annual per capita water availability is 
expected to further drop down to $1,533 \mathrm{~m}^{3}$ by 2050 (Fig. 1). In the developing nations like India and African countries, $80-90 \%$ of water is used for agriculture purposes and only $2-5 \%$ is used for industrial purposes as was estimated for the year 2000 (Fig. 2).

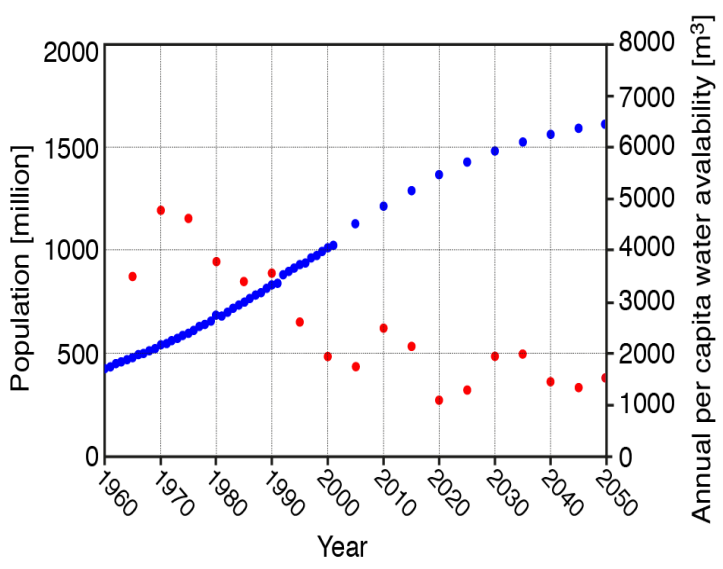

Fig. 1. Annual per capita water availability in India

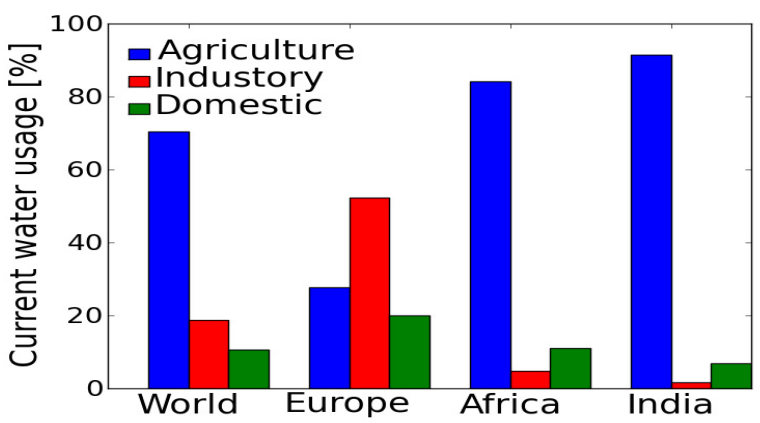

Fig. 2. Usage of water in different sector in world during 2000

\section{B. Quality}

The quality of existing water supplies will become a further concern in some regions of the globe. Water acquires most of its geochemical and biochemical substance during its cycle from clouds to rivers, through the biosphere, soils and geological layers. Changes in the amount or pattern of precipitation will change the route/ residence time of water in the watershed, thereby affecting its quality. As a result, regardless of quantity, water could become unsuitable as a resource if newly-acquired qualities make it unfit for the required use [10]. For example, in areas with relatively high water table, or under intensive irrigation, increased evaporation due to higher temperature will raise the concentration of dissolved salts. Further, increased flooding could raise water table to the point where agrochemicals/ industrial wastes from soil leach into the groundwater supply.

Likewise, higher ocean level will lead to salt water intrusion in coastal groundwater supplies, threatening the quality and quantity of freshwater access to large population.

\section{Accessibility}

The water quantity and quality decrease as a result of intensification of the hydrological cycle, competition for available resources will intensify. Demand for agricultural and domestic water in particular increases significantly at hotter and drier times of the year. Agriculture has always been the dominant end-use of diverted water; this will only intensify with increasing need for irrigation brought on by higher temperatures and reduced precipitation, coupled with increasing populations [11]. Meanwhile, demands of industry are expected to become a greater issue in the competition for dwindling resources; in the event of decreasing water table as a result of climate change, industrial needs will be forced to compete with agricultural and domestic water supply sources, and could lead to conflict.

\section{RESOURCES, AVAILABILITY AND IMPACTS OF GROUNDWATER}

Ground water resource is a replenishable but finite resource. Rainfall is the principal source of recharge, though in some areas, canal seepage and return flow from irrigation also contribute significantly to the groundwater recharge. Groundwater resource comprises of two parts -dynamic resource in the zone of water-table fluctuation which reflects seasonal recharge and discharge of aquifers and static resource below this zone, which remains perennially saturated [12]. India stresses that 'exploitation of groundwater resources should be so regulated as not to exceed the recharging possibilities, as also to ensure social equity'[13]. Thus, the dynamic groundwater resource is essentially the exploitable quantity of groundwater, which is recharged annually. A complexity of factors hydrogeological, hydrological and climatological - controls the groundwater occurrence and movement. Only freshwater was included and saline areas were not included in the assessment of groundwater resources in various studies [14]. Further, annually replenishable component of groundwater was considered for use in developmental planning. The replenishable groundwater resource was essentially a dynamic one, which is replenished annually or periodically by rainfall, irrigation return flow, canal seepage, tank seepage, etc. [15]. Notwithstanding the need to prioritize the issue of aquifer depletion, in an increasing number of regions in India (Fig. 3) groundwater pollution could render the resource useless before it is exhausted.

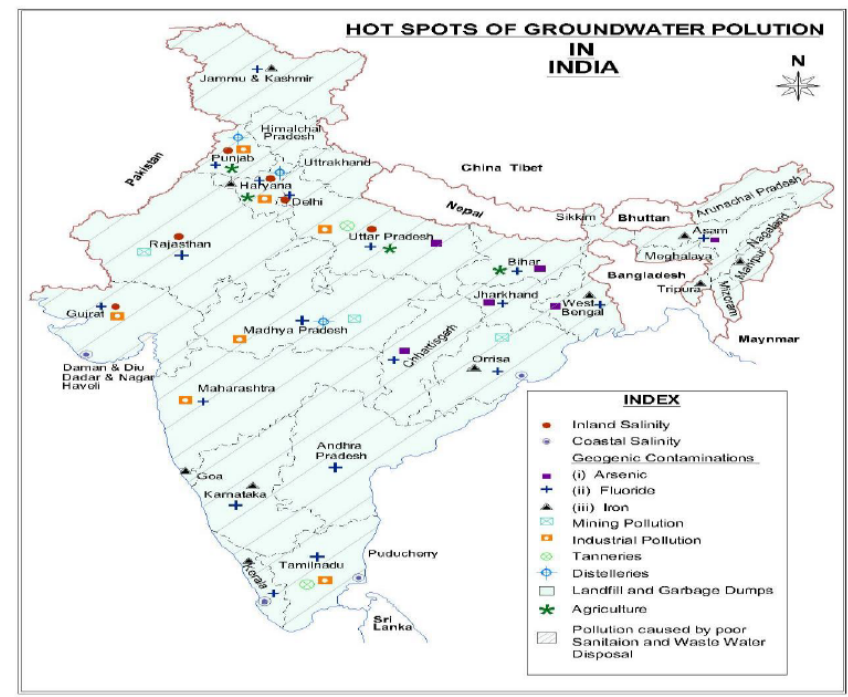

Fig. 3. Hot-spots states of groundwater pollution in India

The groundwater impacts result in spatial and temporal changes in precipitation, it will significantly influence natural 
recharge. Moreover, since a good deal of natural recharge occurs in areas with vegetative cover, such as forests, changing earth temperature resulting from rising temperature may reduce infiltration rates from natural precipitation and thus reduce recharge. Recharge responds strongly to temporal pattern of precipitation as well as soil cover and soil properties.

The Indo-Gangetic aquifer system has been getting heavy recharge from the Himalayan snow-melt. As snow-melt-based run-off increases during the coming decades, their contribution to potential recharge may increase however, a great deal of this may end up as 'rejected recharge' and enhance river flows and intensify the flood proneness of eastern region [12] As the snow-melt-based run-off begins declining, one should expect a decline in run-off as well as groundwater recharge in this vast basin. A major interplay of climate change and groundwater will be witnessed in coastal areas.

\section{Hydro-Climatic Change and Groundwater ECONOMY: CARBON FOOTPRINT}

Climate change is expected to significantly alter India's hydroclimatic regime over the $21 \mathrm{st}$ century. It is widely agreed that the Indo-Gangetic basin is likely to experience increased water availability from snow-melt up to around 2030 but face gradual reductions. Parts of the Indo-Gangetic basin may also receive less rain than in the past; but the rest of India is likely to benefit from greater precipitation [16]. According to IPCC, most Indian landmass below the Ganges plain is likely to experience a $0.5-1{ }^{0} \mathrm{C}$ rise in average temperatures during $2020-2029$ and $3.5-4.5{ }^{0} \mathrm{C}$ rise in 2090-2099 [3]. Many parts of peninsular India, especially the Western Ghats, are likely to experience a $5-10 \%$ increase in total precipitation; however, this increase is likely to be accompanied by greater temporal variability. Throughout the sub-continent, it is expected that 'very wet days' are likely to contribute more and more to total precipitation, suggesting that more of India's precipitation may be received in fewer than $100 \mathrm{~h}$ of thunderstorms - and half in less than $30 \mathrm{~h}$ - as has been the case during recent decades[17]. This is likely to mean higher precipitation intensity and larger number of dry days in a year. Increased frequency of extremely wet rainy seasons is also likely to mean increased run-off.

India's water policy making is yet to fully factor in this epochal transformation in the way its farmers water their crops; and government keep investing billions of dollars on new surface reservoirs and canal networks even as the existing ones have begun falling into disuse. In contrast, the net area served by groundwater has been steadily rising. Small farmers looking for opportunities to intensify and diversify their agriculture need year-round irrigation on-demand with great frequency. Tanks and canal systems are unable to meet this need except groundwater wells. Groundwater wells are also a better insurance against a drought than tanks and canal systems.

Transformation of Indian irrigation from gravity-flow to lift has made it highly energy-intensive, but the arithmetic of computing the carbon footprint on economy is fraught by widely divergent estimates. In year 2000, Indian farmers lifted some $150 \mathrm{~km}^{3}$ of groundwater using electric pumpsets and around $80 \mathrm{~km}^{3}$ using diesel pumpsets. Lifting $1000 \mathrm{~m}^{3}$ of water to a height of $1 \mathrm{~m}$ uses upto $2.73 \mathrm{kWh}$ of energy without friction losses and at peak efficiency [18]. Indian electric irrigation pumps probably operate at $40 \%$ efficiency; moreover, transmission and distribution losses in delivering power to pumpsets are of the order of $25 \%$ or higher. This implies that the electricity actually used to lift $1000 \mathrm{~m}^{3} \mathrm{~m}^{-1}$ in the order of $9.1 \mathrm{kWh}$ [18]. The most important determinant of the Carbon footprint of India's pump irrigation economy is the dynamic head over which farmers lift water to irrigate crops. The larger the head, the higher the energy consumption and the more likely that electrified deep tube wells are used for pumping groundwater, multiplying the Carbon footprint of groundwater pumping.

\section{AdAPtATION AND Mitigation FOR GROUNDWATER RECHARGE}

The groundwater hotspots are concentrated in arid and semi-arid areas of western and peninsular region, especially in the seven states of Punjab, Rajasthan, Maharashtra, Karnataka, Gujarat, Andhra Pradesh, and Tamil Nadu, as is evident from the study of groundwater over-exploited areas. Continued over-exploitation of groundwater has severely curtailed the resilience of their aquifers and their ability to stabilize farming livelihoods in the face of heightened hydro-climatic variability [11]. Groundwater is pumped from great and increasing depths mostly using coal-based electricity; hence, these are also the regions which account for an overwhelmingly large proportion of GHG emissions from groundwater pumping. Accepting the present groundwater dependence of agriculture as a fait accomplished should lead policy makers to evolve a strategy of 'proactive management of aquifer storage' as the central plank of India's water strategy in the years to come. This strategy needs to incorporate effective means to manage agricultural water demand as well as to enhance natural groundwater recharge through large-scale 'managed aquifer recharge' investments.

The groundwater recharge is shaped by the experiences and technologies used in the western United States and Australia. As a result, Indian government, the hydro-geologists tend to prefer large spreading type recharge structures rather than working with millions of well owners to modify their wells for recharge. India needs to use the vast technological experience of Australia and the US to design recharge programs but in a manner that incorporates its unique features. While there is no substitute for large spreading type recharge structures in recharging large confined aquifers, not using millions of farmer-owned open wells for recharge is a great opportunity lost [19].

\section{CONCLUSION}

Reorienting India's water strategy to meet the challenge of hydro-climatic change demands a paradigm change in the official thinking about groundwater management. Although the groundwater agencies are the custodians of groundwater 
resource, in reality, multiple agencies in public and private sectors are major players in groundwater economy. As climate change transforms groundwater into a more critical and yet threatened resource, there is essential need for coordinating mechanisms to bring these agencies under an umbrella framework to synergize their roles and actions. Even as governments evolve groundwater regulations and their enforcement mechanisms, more practical strategies for groundwater governance need to be evolved. Synergizing the working of agencies in these spheres offers the best chance to bring a modicum of order and method to the region's water scavenging irrigation economy.

Public agencies with strong science and engineering capabilities need to play a major role in constructing and managing large recharge structures. An intelligent strategy can involve millions of farmers and householders-and thousands of their communities-each of whom can contribute small volumes to recharge dynamic groundwater. The groundwater recharge is to be a major response to hydro-climatic change, needs to evolve and work with an integrated groundwater recharge strategy with roles and space for various players to contribute. Pursuing such methods could be the best feasible response to climate change mitigation as well as adaptation in groundwater management.

\section{REFERENCES}

[1] R. H. Moss et al., "The next generation of scenarios for climate change research and assessment," Nature, vol. 463, pp. 747-756, 2010.

[2] P. C. D. Milly, J. Betancourt, M. Falkenmark, R. M. Hirsch, Z. W. Kundzewicz, D. P. Lettenmaier, and R. J. Stouffer, "Stationarity is dead: Whither water management?" Science, vol. 319, pp. 573-574, 2008.

[3] Intergovernmental Panel on Climate Change (IPCC), Climate Change 2001: Synthesis report, Cambridge University Press, New York. 2001.

[4] T. R. Karl, J. M. Melillo, and T. C. Peterson, Global Climate Change Impacts in the United States. Cambridge University Press, New York, 2009.

[5] K. Freas, B. Bailey, A. Munevar, and S. Butler, "Incorporating climate change in water planning," Journal of the American Water Works Association, vol. 100, pp. 6, June, 2008.

[6] IPCC, Climate Change 2007: The Physical Science Basis. Contribution of Working Group I to the Fourth Assessment Report of the Intergovernmental Panel on Climate Change, S. Solomon, D. Qin, M. Manning, Z. Chen, M. Marquis, K. B. Averyt, M. Tignor and H. L. Miller (eds.). Cambridge University Press, Cambridge, UK and New York, 2007.
[7] W. N. Adger, H. Saleemul, K. Brown, D. Conway, and M. Hulme, "Adaptation to climate change in the developing world," Progress in Development Studies, vol 3, no 3, pp. 179-195. 2003.

[8] M. Alam, A. Rahman, M. Rashid, G. Rabbani, P. Bhandary, S. Bhadwal, M. Lal, and M. Soejachmoen, "Impacts, vulnerability and adaptationto climate change in Asia," Background Paper, produced for the UNFCCC Asia Regional Workshop on Climate Change Adaptation, Beijing China, 11-13 April 2007.

[9] E. P. Maurer, L. Brekke, T. Pruitt, and P. B. Duffy, "Fine-resolution climate projections enhance regional climate change impact studies," Eos Trans, vol. 88, no. 47, pp. 504, August, 2007.

[10] UNICEF. (2001). Safe Drinking Water, [Online]. Available: http://www.unicef.org/specialsection/about/sgreport-pdf/03_SafeDrin kingWater_D7341Insert_English.pdf.

[11] FAO, Water Report 36. (2011). Climate change, water and food security. [Online]. Available: http://www.fao.org/docrep/014/i2096e/i2096e.pdf.

[12] M. Q. Mirza, R. A. Warrick, N. J. Ericksen, and G. J. Kenny, "Trends and persistence in precipitation in the Ganges, Brahmaputra and Meghne river basins," Hydrological Sciences Journal, vol. 43, no. 6 , pp. 845-858, 1998.

[13] MOWR, "National Water Policy," Ministry of Water Resources, Government of India, 2002.

[14] G. B. Pant and K. R. Kumar, Climates of South Asia, John Wiley \& Sons Ltd., West Sussex, U.K., 1997.

[15] World Commission on Dams (WCD), Dams and Development. (2000). [Online]. Available: http://www.dams.org.

[16] S. I. Hasnain, "Report on Himalayan Glaciology," International Commision on Snow and Ice (ICSI), U.K., pp. 221999.

[17] A. K. Gosain and S. Rao, "Impact assessment of climate change on water resources of two river systems in India," Jalvigyan Sameeksha, vol. 22, pp. 21, 2007.

[18] G. C. Nelson and R. Robertson, "Personal communication Planning Commission," Report of the Expert Group to Review the Issue of Groundwater Ownership in the Country, 2008.

[19] T. Shah, "India's master plan for groundwater recharge: an assessment and some suggestions for revision," Econ. Polit. Weekly, vol. 43, pp. $41-9,2008$.

Khajuria Anupam is originally from India, who was born in year 1983. She graduated Masters in the field of Environmental Sciences from India. She graduated Ph.D. in Environmental Engineering from Osaka University in the field of sustainable energy and waste management. Presently she is doing Postdoc in Tokyo institute of Technology, Tokyo in the field of climate change and hydrology. Her research interest is in environmental management regarding the water issues, environmental modeling simulation and social-economic factors of society.

Kanae Shinjiro is working as an Associate Professor in the Tokyo institute of Technology, Tokyo in the field of Hydrology and Environmental Informatics. His research interest is in water issues with modeling simulation of Global Circulation models. 